\title{
Intelectualismo ético de Platón: relación de gnoseología y ética a partir del libro VII de la República*
}

\author{
[Artículos]
}

\author{
Estiven Valencia Marín ${ }^{* *}$
}

Recibido: 20/03/202O

Aprobado: 18/05/2020

Citar como:

Valencia, E. (2020). Intelectualismo ético de Platón: relación de gnoseología y ética a partir del libro VII de la República. Análisis, 53(98).

https://doi.org/10.15332/214.59169.5556

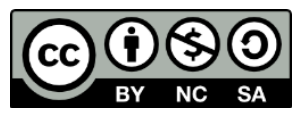

\section{Resumen}

El conocimiento ha incursionado como tema de gran alcance dadas las múltiples disciplinas que lo evocan y cuyos intereses investigativos incurren en una definición para este. Primeras cavilaciones acerca del conocimiento se adelantaron bajo una óptica dualista de materialismo e idealismo, ambas posturas de carácter filosófico que determinaron el

\footnotetext{
* Artículo de reflexión derivado de investigación formativa, realizada en la Universidad Tecnológica de Pereira en torno al problema de los fundamentos gnoseológicos para el desarrollo ético-moral desde el pensamiento platónico. En cuanto al uso de términos en griego, paralelos a la versión castellana de las citas sobre Platón que se toman de los diálogos desarrollados por la editorial Gredos, se usa la edición del inglés Ioannes Burnet y su Opera Platonis (1928).

** Licenciado en Educación Religiosa, catedrático y miembro del grupo de investigación del Fenómeno Religioso en la línea de Filosofía y Religión de la Universidad Católica de Pereira. Maestrante y Licenciado en Filosofía de la Universidad Tecnológica de Pereira, coinvestigador y colaborador logístico del grupo de investigación de Filosofía Antigua. Correo electrónico: estiven.valencia@ucp.edu.co; ORCID: https://orcid.org/00000001-9652-7701
} 
pensar de Occidente. Dicho así, desde la Grecia clásica pensadores como Platón, entre otros clásicos, entronizaron esta cuestión, pero dicho trato dualista en el ámbito del saber estuvo fuertemente vinculado con una reflexión de talante ético del que Platón no se eximió. Con lo dicho, el presente artículo busca describir los postulados gnoseológicos y éticos en Platón con el fin de esclarecer el nexo entre conocimiento y práctica humana.

Palabras clave: Filosofía Antigua, Ética Platónica, Gnoseología, Intelectualismo Moral, República de Platón.

\section{Plato's ethical intellectualism: relation of gnoseology and ethics from book VII of The Republic}

\section{Abstract}

Knowledge has become a subject of great scope given the multiple disciplines that evoke it and whose research interests incur in a definition for it. The first disquisitions on knowledge were made under the dualistic view of materialism and idealism, both philosophical positions that determined the thinking of the West. Thus, since Classical Greece, thinkers such as Plato, among other classics, exalted this issue, but such dualistic treatment in the field of knowledge was strongly related to an ethical nature from which Plato himself was not released. This said, this article seeks to describe the gnoseological and ethical postulates in Plato in order to clarify the nexus between knowledge and human practice.

Keywords: ancient philosophy, Plato's ethics, gnoseology, moral intellectualism, Plato's Republic. 


\section{Intelectualismo ético de Platão: relação da gnoseologia e ética do livro VII da República}

\section{Resumo}

O conhecimento entrou como um assunto de grande alcance dadas as múltiplas disciplinas que o evocam e cujos interesses investigativos incorrem numa definição para ele. As primeiras reflexões sobre o conhecimento foram avançadas sob uma perspectiva dualista de materialismo e idealismo, ambas posições de natureza filosófica que determinaram o pensamento do Ocidente. Dito isso, desde a Grécia clássica, pensadores como Platão, entre outros clássicos, entronizaram essa questão, mas esse tratamento dualista no campo do saber estava fortemente ligado a uma reflexão da disposição ética da qual Platão não se isentava. Com isso, este artigo busca descrever os postulados gnoseológicos e éticos em Platão, a fim de esclarecer a ligação entre conhecimento e prática humana.

Palavras-clave: Filosofia Antiga, Ética Platônica, Gnoseologia, Intelectualismo Moral, República de Platão. 
En qué consista y cómo se practique la virtud, no será resuelto por el estudio de la conducta humana en cualquiera de sus manifestaciones, sino que exige de una previa posición abstracta del sentido del problema expreso. Juan Nuño. El pensamiento de Platón

\section{Introducción}

El filósofo Platón (427-347 a. C.), quien fue un discípulo de Sócrates y adoptó el método dialéctico para hacer filosofía tal cual se evidencia en sus múltiples escritos, dejó consignado a excepción de su maestro el pensamiento proferido en su tiempo. Con él, estableció bases de talante objetivo y firmes para la definición de las virtudes estimadas por cualificaciones que posibilitan las opiniones correctas, además de ser un fundamento para la construcción de valores de la cultura. En esta misma línea, Sócrates (470-399 a. C.) como antecedente de cimientos conceptuales para la ética, la antropología, gnoseología, la cosmología y educación en Platón, preconiza una reflexión intelectual dialogada - asumiendo que este trasmitía su erudición oralmente- sobre las acciones del hombre supeditada a la temática político-moral, y que el mismo filósofo adepto de Sócrates acentúa en su proyecto reflexivo con el propósito de justificarlo.

Si bien exponer los asuntos relevantes de la filosofía platónica es el interés en el presente texto, la exhibición de la teoría de las ideas o formas, partiendo de la concepción dual de la realidad en tanto hay un mundo

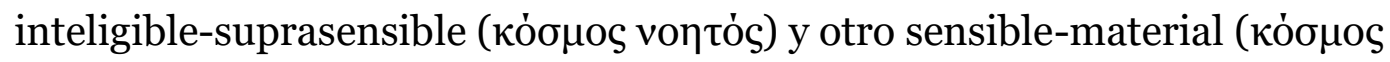
ópatòs), ha sido de especial interés tanto para una crítica como para la 
aceptación en corrientes de pensamiento ulteriores a Platón que se desarrollaron en el transcurso de la historia. En general, ese mundo sensible o visible es solo la parte inferior de la realidad, un estado nimio de verdad pues de los objetos se define lo que son al constituirse en otra existencia que guarece conceptos/ideas para las cosas según Rowe (citado en Gill, 2005, p. 217). Sin embargo, el acceso a la verdad de las cosas por mor de las aptitudes reflexiva y discursiva, inherentes al hombre dotado de $\lambda$ óyos (razón), reside en la delimitación y determinación del principio material por parte del formal (Reale, 2001, p. 191). Desde este argumento, se desmiente una absoluta separación de mundos.

En efecto, el tránsito de lo sensible a lo inteligible gracias a la razón posibilita un conocer las ideas, empero dicho conocimiento presupone de ciertos medios como son las virtudes tal como se muestra implícito en el siguiente fragmento platónico: "Si triunfan las mejores partes de la mente que hacen a un régimen de vida arreglado y la filosofía, pasan a una vida feliz" (Fedro, 256b). De esta manera, es el hombre reflexivo el que se orienta desde la razón y con apoyo de la virtud para hacerse con correct ethical judments, juicios relativos a la consecución del bien social que deben fundarse en naturalezas fijas y estables tal cual sostiene Ferejohn (citado en Benson, 2006, p. 153). Discernir, entonces, los medios para conocer y cómo las ideas inciden en las acciones resulta un posible insumo para argüir el nexo conocimiento-praxis el cual se intenta demostrar en este texto.

Con base en estos presupuestos que perfilan ser una escueta presentación del pensamiento platónico y que se ha de profundizar en los próximos acápites, el presente artículo tiene por objetivo el esclarecer los elementos teóricos de los que Platón se sirve para justificar el conocimiento de lo real, a partir de la dimensión práctica del hombre desde el libro VII de la 
República que integra el corpus platonicum, y posteriormente reflexionar sobre los argumentos que subsumen el aspecto ético al conocimiento. Para ello se requiere, previamente, explorar de modo sucinto en una serie de apartados, los fundamentos de la teoría del conocimiento referenciada por la moción de las ideas u objetos del saber, y recopilar los principales juicios respecto de la dimensión ética como un componente para el desarrollo individual y social de la humanidad, siendo la gnoseología y la ética temáticas que sintetizan de todo el pensamiento platónico.

\section{Generalidades a la teoría del conocimiento en Platón}

El tratado gnoseológico en Platón no tiene intención sistemática en comparación con autores como Aristóteles, quien optó por exponer sus ideas a través de opúsculos dedicados a un tema específico. La obra platónica, por lo general, aborda múltiples cuestiones entre las que sobresale la posibilidad y condiciones del saber, tema ampliamente escrutado en sus diálogos -República, Menón, Sofista, Teeteto, entre otros-. Cierto es que el problema del conocimiento ha sido una cuestión muy abordada con anterioridad a Platón, caso especial del eleata Parménides para quien existe una diferencia entre opinión y verdad, pero es de considerar que en ambos pensadores la definición de la opinión - como aspecto que comprende los datos de los sentidos inaprehensibles en su naturaleza, en su esencia - y la verdad -que integra la concepción de un saber esencial por cuanto no está sometido a cambios, ni mucho menos alberga contradicciones- hace parecer que comparten ciertas consideraciones.

La verdad que concibió Parménides con carácter de objetividad rebasa los saberes que ofrecen los sentidos por cuanto son relativos, lo cual orientó en Platón la distinción de lo inteligible-real y lo sensible-aparente. No obstante, su fidelidad hacia tales presupuestos se vio cercenada, según 
Cornford (1989), por reconocer para el mundo aparente su participación en lo real (p. 139). Asimismo, prescindir de los sentidos es derogar el inicio mismo de la actividad epistémica, un desconocer los estímulos que suscitan ejercicios de intelección tal cual profiere el joven Teeteto al respecto de la fuente del saber en el diálogo homónimo. Frente a este argumento, Platón no duda en referir a Protágoras por cuanto él sostiene que todo saber depende de la percepción: "De hecho el que sabe algo

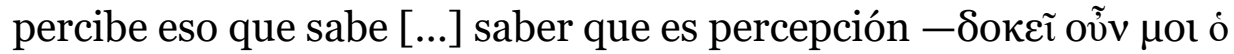

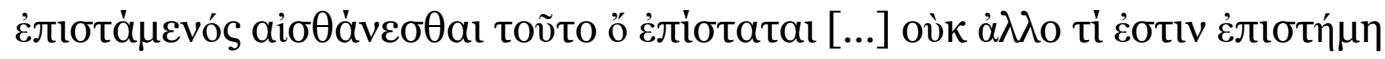

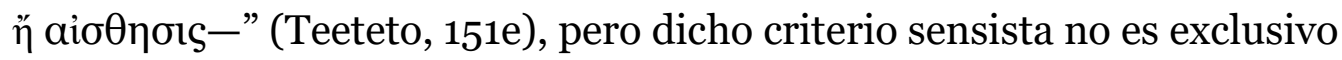
generador del proceso de conocimiento.

Consecuencia de esto, Platón afirma que toda percepción sensible no es la única forma del conocimiento, mas existe otra forma de saber que trasciende el límite sensitivo: "El saber no radica en nuestras impresiones sino en el razonamiento que hacemos de ellas. Allí nos es imposible aprender el ser y verdad, pero aquí es posible" (Teeteto, $186 \mathrm{~d}) .{ }^{1}$ En esencia, el saber verdadero refiere al ser de las cosas, no a las cosas mismas que están sometidas a trasformaciones que pueden contrariar la infalibilidad y objetividad buscadas. De esta manera, la distinción gradual entre realidades que Platón acepta como suya desde el pensar eleata: mundo

\footnotetext{
${ }^{1}$ Respecto de este fragmento tomado del Teeteto (186d), es uno de los muchos fragmentos que dan pie al postulado platónico de la teoría de las Ideas o de las

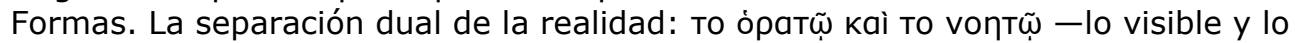
inteligible- de la que procede dicho tratamiento, alude específicamente a los tratados presocráticos del eleata Parménides y del efesio Heráclito respectivamente. El problema de lo uno y lo múltiple ha estado en vigencia hasta la aparición de Platón, pese a que, como sostiene Cornford (2007): "los objetos percibidos no pueden ser los únicos objetos del conocimiento como lo implicaba la identificación del conocimiento con la percepción [...] todo conocimiento de la verdad que es algo distinto del trato inmediato con los datos sensibles, implica relación con las Formas que no son objetos de percepción ni están comprometidas con el flujo heraclíteo" (pp. 142-143), dejando entredicho que para el pensador clásico en cuestión existe aún dicha diferencia. Sin embargo, estos presupuestos platónicos parecen ser un aporte a la solución de semejante problema por cuanto lo uno y lo múltiple son instancias útiles para la comprensión integral del mundo.
} 
inteligible y el mundo sensible a los cuales pertenecen las ideas y los objetos externos respectivamente, es ese germen de la teoría de las ideas y el núcleo y propuesta insigne de todo su pensamiento.

En cuanto a las ideas o formas ( $\varepsilon \tilde{i} \delta \eta)$, estas son objetos del conocimiento cuyas características de inmateriales, inmutables y eternas las hace existentes en el complejo ejercicio del pensar y, por demás, representan una conceptualización objetiva de las cosas. Esto se dice porque todas las عỉঠń son solamente cognoscibles por vía de la razón, pues se tratan de afirmaciones o proposiciones como presenta Ross (1993), que no proceden de percepción en tanto que no poseen propiedad física alguna. Confirma esta idea Platón, ofreciendo una descripción sucinta del mundo inteligible

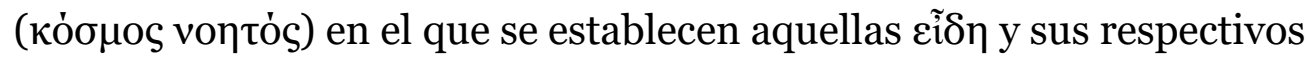

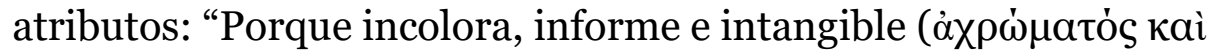

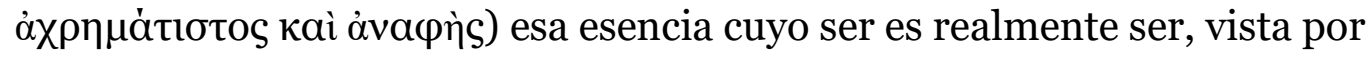
el entendimiento y alrededor del cual crece el verdadero saber ( $\dot{\alpha} \lambda \eta \theta$ oṽ $\varsigma$

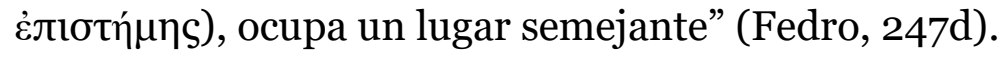

Anexo a tal conjetura, la teoría del conocimiento platónico se funda en otros aspectos: los grados del saber y las facultades del alma como elementos propiciadores del saber. En primer lugar, el alma, fundamentalmente entendida como principio de racionalidad de carácter divino e inmortal, además de cauce vital (dicho de otro modo, participa de una no procedencia del mundo sensible) es una entidad afín a las ideas inmateriales y eternas arraigadas en el ámbito inteligible, aunque no se trate de un عĩoos más (Ross, 1993, p. 43). Empero, la unión de alma con el cuerpo que Platón dice efecto de una caída, deja expuesta una escisión entre tales componentes que hacen del alma intermediaria entre lo inteligible y visible cuyos intereses son eminentemente cognoscitivos (Nuño, 1988, p. 77), tal cual se expresa en la célebre alegoría del carro 
alado: "Si es perfecta y alada [el alma] surca las alturas y gobierna el cosmos, pero la que ha perdido sus alas se agarra de lo sólido donde se asienta, y se hace con el cuerpo" (Fedro, 246b-c).

Con base en esta alegoría de solvencia órfica-pitagórica, se percibe que las almas unidas al cuerpo son consecuencia de algún desorden o culpa contraída; no obstante, esta relación se destaca como transitoria, es decir,

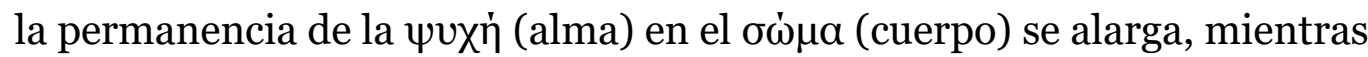
fenece la existencia terrena. Ahora, pensar esta noción mítica en el orden del saber implicaría decir que, si propio del alma es el supeditarse al mundo de las ideas y su actividad no es más que escrutar el ser de los objetos particulares, de explicarlos adecuadamente en términos de Fine (2003, p. 226), mientras esté sometida al cuerpo es necesario, por vía de purificación, disponerse para la aprehensión de las cĩ்ๆ. Tal proceso asiente dominar las pasiones, surgidas de necesidades somáticas que aquejan al alma en su tarea de atender a la adquisición de la verdad por vía de esas ideas: "Reflexiona óptimamente [el alma] cuando no la perturba esas cosas [necesidades del cuerpo] sino que aquella se encuentra en sí misma [...]" (Fedón, 65c).

Seguidamente, la cuestión de los grados del saber según los cuales se concibe a esta como proceso in crescendo desde lo sensible hasta la aprehensión de los conceptos/ideas que indican un nivel de realidad más pleno, no quita importancia a los sentidos. Para este caso, los componentes sensitivos, al igual que la percepción, se identifican con el conocimiento dado que el contacto con estos no solo activa facultades sensibles e intelectuales para hacer entendibles los datos de la experiencia (Boeri, 2007, p. 92), sino que también precisa de un aspecto anamnético propio de la gnoseología platónica. 
En este sentido, un rasgo necesario para el conocimiento de ideas es la

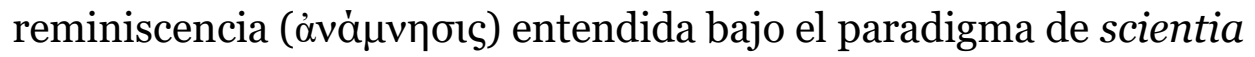
memoria est, que estima la aceptación parcial de lo sensible en el saber, a pesar de tener las sensaciones una incapacidad de revelar la naturaleza de las cosas, es decir, el ser de estas y que, además, necesitan de una intervención de la razón para la adquisición del saber verdadero.

Así, por la reminiscencia Platón atiende a la preexistencia del alma y a su saber adquirido antes de someterse al cuerpo: "el alma inmortal, habiendo nacido muchas veces y viendo todas las cosas tanto las de aquí como las del Hades, no hay nada que no haya aprehendido" (Menón, 81c)², y asegura en la dimensión sensible un estado de expectación al recuerdo de aquellas ideas que olvida el alma tal cual se nota implícito en el discurso de Diotima adosado a lo bello en sí: "Quien quiera ir por el recto camino comience a dirigirse hacia los cuerpos bellos [...] luego considerar la belleza del alma [...]" (Banquete, 210a-c). No obstante, Platón alega la distinción de los modos de saber usados por el acervo eleático: la opinión que se forma desde la experiencia sensible y la ciencia de la que emerge verdad.

Con los elementos descritos, aquel mundo de realidades perfectas hizo méritos a la defensa platónica de que el hombre partícipe de lo sensible no tiene únicamente en las sensaciones medios de saber si bien existen

\footnotetext{
2 Tal fragmento tomado del diálogo del Menón que reflexiona al respecto de la naturaleza de la virtud, traduce: "el alma, pues, siendo inmortal y habiendo nacido muchas veces, y viendo efectivamente todas las cosas, tanto las de aquí como las del Hades, no hay nada que no haya aprendido" (81c). En la misma línea y cotejando con otros diálogos del Platón, en el Fedón se expresa lo mismo en boca de Cebes quien toma palabras de Sócrates, tras la discusión al respecto de la inmortalidad del alma: "[...] el aprender no es otra cosa sino recordar, y según este es necesario que de algún modo nosotros hayamos aprendido en algún tiempo aquello de lo que ahora nos acordamos. Y eso es imposible al menos que nuestra alma haya existido en algún lugar, antes de llegar a existir en esta forma humana" (173a). Tal argumento de herencia órfico-pitagórica es el sustento teórico en el que Platón se basa para justificar la preexistencia del alma.
} 
accesos a otros modos de conocimiento, que perfilan ser estados superpuestos a la simple experiencia. Ahora bien, la racionalidad que distingue al hombre de otros seres vivientes no solo recae en la comprensión de las ideas, sino también en la capacidad reflexiva de cara a las acciones que ejecuta y se funda en la razón. De hecho, la virtud se convierte en instrumento de la ya mencionada purificación del alma, si bien es esta la que somete a examen todos los elementos distintos de su

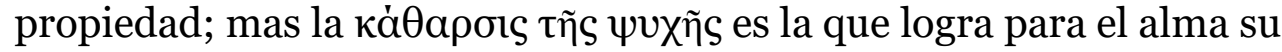
atención en lo que le verdaderamente le compete, en lo que le conviene: un proceso que se impone al dominio de las siempre presentes apetencias somáticas.

\section{Generalidades del proyecto ético de Platón}

Las ideas de justicia, de bondad, templanza, prudencia, etc., presentes en el pensamiento platónico se convirtieron en materia de discernimiento para la elección de lo que es conveniente al desarrollo individual del sujeto y el de la sociedad a la que pertenece, de aquí la articulación de ética y política. Pero más allá de tales mociones, es perentorio indicar la importancia no solo del argumento de las ideas ( $\varepsilon i \tilde{\delta} \delta \eta)$ en el proyecto ético de Platón, sino también la célebre partición antropológica cuerpo-alma

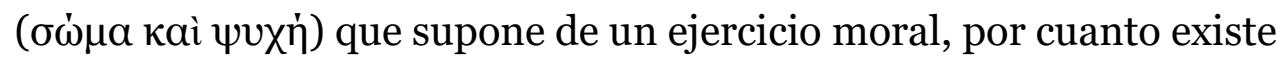
existen fines incompatibles entre dichos componentes. Según Annas (1981), el allma y el cuerpo explicitan un principio de conflicto e instan a todas las personas a buscar fines distintos (pp. 141-142). Dicho así, el alma que posee propiedades como la inmaterialidad y la inmortalidad, y cuyas facultades abrazan la actividad racional y moral del ser humano, convive transitoriamente con el cuerpo cuyos caracteres materiales y corruptibles le hacen semejante a la dimensión que pertenece: lo sensible. 
Por ello, al poseer propias exigencias e inclinaciones, la atención para con las necesidades del cuerpo ameniza las preocupaciones del alma hasta el punto de decir que el aquel es un monumental obstáculo del que el alma debe despojarse para recuperar sus atributos y luego retornar a sus orígenes divinos. De hecho, el $\sigma \omega \dot{\mu \alpha}$ se entiende desde Platón como un lastre para los verdaderos intereses humanos por mor de las apetencias a las que se haya sometido. Según Fred Miller (citado en Benson, 2006, p. 281) los deseos o apetitos revelan la naturaleza compleja del hombre en tanto envuelve capacidades conativas y cognitivas que, sin transitar por una depuración, quedan imposibilitadas de atender a lo mejor, esto es, en términos de Platón, el ejercicio intelectual. Entonces el intelecto es verdadero interés que, al decir de Châtelet (1995) en uno de sus comentarios respecto de la moral platónica, comporta un dominio de los deseos:

[...] a lo que debe tender el individuo es a realizar la mejor jerarquía, a conseguir que las concupiscencias se sometan al valor, y este a la razón. Trátese siempre de liberar la parte divina del alma: esta ascensión purificatoria puede llevarse a cabo mediante el ejercicio intelectual, parte calculadora dando firmeza y aumentando su poder hasta lograr mantener a nivel a las otras partes del alma. (p. 127)

Hablar de otras partes del alma remite a la alegoría del carro alado condensada en el citado diálogo del Fedro, en el cual se estima una triada de funciones en el alma, a saber: función racional, actuación irascible y parte concupiscible, representadas las dos últimas por corceles cuyas actitudes o comportamientos de docilidad y de rebeldía ilustran todas las inclinaciones en ocasiones sobrias y en otras disonantes (246a-b). Dichas inclinaciones o tendencias anímicas ganan fama de malsanas cuando el ser humano que se deja dominar por tales no logra para sí 
estados de bienestar. Este es identificado entre algunos pensadores

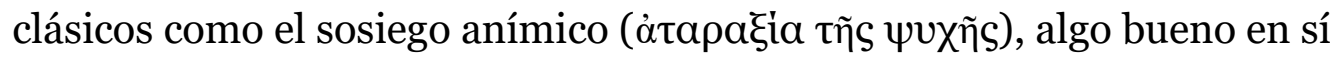
mismo que se entiende a la luz de la regularidad y el orden establecidos entre las partes de un todo, según propone Mason (citado en Herrmann et ál., 2007, p. 200). Por estar sometido a un proceso de purificación de tales tendencias desde la recta satisfacción de estas, el ser humano se procura estados de tranquilidad deseados.

Por lo demás, el iteradamente referido proceso de purificación o de depuración que Platón presenta en términos de "salida de los prisioneros y posterior dejación de las cadenas" (República, 514a-517a) figura, también, como actividad moral a la que está llamado todo hombre que no desea coexistir con otros irreflexivamente. Análoga al campo de esas tendencias volitivas y apetitivas del ser humano, la causa catártica a la que este se somete implica una atención a la proporción, esto es, una aptitud moderada respecto a deseos que imbrican en la existencia humana, de manera que abogan por una satisfacción de quereres que no estiman

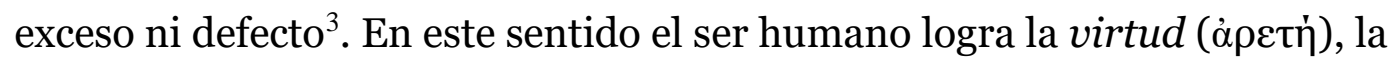
cual comporta una disposición para identificar acciones correctas, y saber cuándo y cómo hacerlas, de tal manera que, por la práctica de estas, se pueda adquirir estados de satisfacción como su más esperada consecuencia.

La mesura en la satisfacción de los deseos, tanto de las partes del alma que corresponden a lo irascible y concupiscible como en relación con la parte

\footnotetext{
${ }^{3}$ No es explicito el empleo de los términos exceso y defecto para definir la virtud en Platón - caso contrario el de Aristóteles para quien, en su obra Ética a Nicómaco,

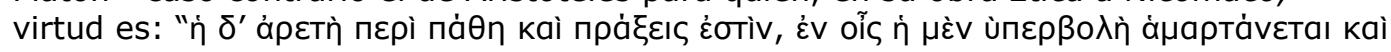

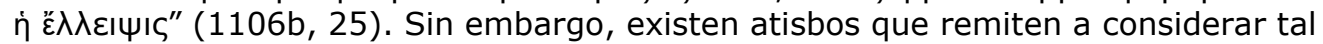

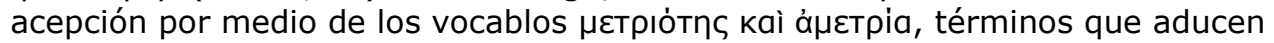
moderación y desmesura respectivamente. Dicho así, pese a que Platón no se refirió al término medio como en Aristóteles - entendido en griego como el $\mu \varepsilon \dot{\sigma o o v}$ - ya en él está implícita tal concepción.
} 
racional, alude a virtudes insignes cuyo ejercicio asiduo procura ajustar de modo conveniente todas las actuaciones humanas. De esta manera, la

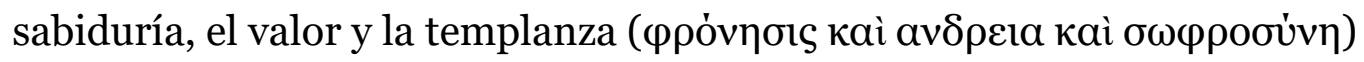
regentan los aspectos racional, irascible y concupiscible, respectivamente (República, 442c-d) ${ }^{4}$. Dicha relación, lograda conjuntamente, tiende a la justicia por la cual el orden y el equilibrio se hacen patentes en la individualidad y colectividad humanas. Esta última virtud hace del sujeto un ser competente para neutralizar sus apetencias, capacidad que asegura lo correcto y conveniente como realización del bien deseado y como un camino para su perpetuación. Así lo interpreta Nuño (1988) en su texto El pensamiento de Platón en los siguientes términos:

[...] la justicia ayuda a comprender la conducta social e individual consecuencia del cumplimiento de la areté, pero no resulta indispensable para conferir sentido a las potencias cognoscitivas del hombre, esto es, a los diferentes tipos del saber relacionados [...] A lo que apunta Platón es a la noción de bien que pasará, luego, a organizar todos los aspectos éticos y políticos, como la revisada estructuración de las relaciones ontognoseológicas. (p. 67)

Análogamente a la teoría de las ideas en la que se evidenció la jerarquía de los saberes, y del cual se colige grosso modo que del mundo sensible no puede emerger ciencia pues el saber que ofrece es limitado para las pretensiones de un saber universal y necesario, Platón sitúa la actividad catártica, actividad propia del filosofar, como medio ineludible para descubrir los objetos de conocimiento inmutables y eternos que

\footnotetext{
${ }^{4}$ De la tradición platónica se hereda la designación de las cuatro virtudes cardinales: justicia, prudencia, fortaleza y templanza, hecho que para la teología medieval y escolástica no pasó inadvertida, aunque se agregan las denominadas virtutes theologicae. Durante el auge del imperio romano, Cicerón ya se había remitido a tales virtudes en su obra De Officiis, además que el emperador filosofo Marco Aurelio en su célebre obra Meditaciones las había compilado.
} 
pertenecen a lo inteligible; esta es la idea suprasensible del bien, que es el canon por el que se valora el grado de realidad y el grado de perfección de lo que se percibe. Desde esta óptica, la idea del bien que configura el mundo inteligible es para Platón el estatus de "lo que aporta verdad a las cosas cognoscibles y otorga al que conoce el poder de conocer [...]" (República, 508e). Por ello, el bien es cúspide de virtudes y de todas las ideas que conforman tanto el mundo de las ideas como el sensible.

De los elementos anteriores se puede inferir, por una parte, que la ética está sujeta al saber del bien, una aplicación de conocimiento general que por antonomasia es criterio estructurante de la realidad tal y como lo asevera el mismo Platón: “[...] A las cosas cognoscibles no solo les viene del bien el ser conocidas, sino también existir aunque este no es esencia sino algo que se eleva más allá en cuanto dignidad y potencia” (República, 509b). Con lo dicho, ello implica decir que el bien es un canal a la unidad de toda la multiplicidad, por cuanto hace inteligible todo lo sensible, dotando de orden y equilibrio esto, que, por sí mismo, no puede darse.

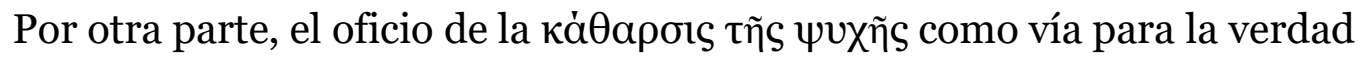
supone de una práctica correctiva en tanto redirecciona a todas las personas en los medios para comprender el mundo. En efecto, el examen de todo prejuicio y la lucha por el establecimiento de un orden anímico frente a la posible disensión entre juicios y deseos, según Platón, determinan al método de purificación (Cornford, 2007, p. 229).

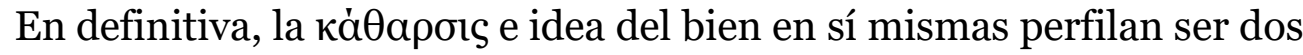
rasgos sustanciales en la reflexión ética de Platón, aquella, por ser medio para el alcance del bien, y esta, como criterio de pensamiento que garantiza la consecución de una vida moral y política. Pero, si bien la sofística se había preocupado por los quehaceres humanos y dejaba de lado las cuestiones físicas que explicaran el origen y estructura del cosmos, 
aún se carecía de ciertas reflexiones que diesen los fundamentos universales para un conocimiento certero. Este suceso Platón lo asume imprimiendo en aquel contexto la racionalidad, que se exhibe contra toda presunción de verdad que pudiese extraviar los deseos en hazañas contraproducentes para el bienestar de sus coetáneos.

Hasta aquí, la reflexión platónica tiene una inspiración sustancialmente práctica y, a la vez política, que discurrirá en una asociación entre la dimensión del conocimiento y la dimensión ética.

\section{Dimensión gnoseológica de la ética en el libro VII de la República}

El ser humano, si bien es un compuesto de cuerpo cuya estructura material le hace perteneciente a lo sensible y cuyas características hacen de este alguien finito, pero también posee un alma en la que ocurre el conocimiento de esas otras realidades que no perecen por cuanto inmutables y eternas, es de considerar que influyen ambos componentes en las prácticas humanas.

Estos postulados que trasvasan los múltiples diálogos platónicos revelan a una teoría de las ideas que incide en los comportamientos a través de la reflexión que suscita un proceso de reorientación al bien. Tal valoración moral del conocimiento resulta explícita por Platón en el siguiente axioma: "La sabiduría y la virtud no son otra cosa que el conocimiento de la justicia, y su desconocimiento es ignorancia y maldad patentes" (Teeteto, 176c).

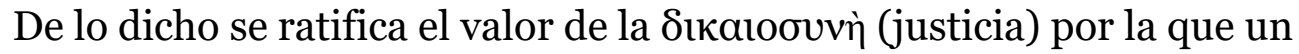
orden y equilibrio se hacen patentes tanto en la individualidad como en la colectividad del hombre, pero que requiere de purificar las apetencias banales para hacerse con la vida intelectiva y manifestar en acciones la 
idea de bondad. He aquí la mutualidad conocimiento y perfeccionamiento moral: si bien la persona que es catalogada de "sabia” y cuyo carácter lo forma el conocimiento de las ideas, no le basta con teorizar acerca de estos objetos del pensar, sobre todo con dar razón de lo que es el bien como idea vértice de lo que constituye el mundo inteligible. De hecho, la idea del bien que da al alma la facultad para extraer la verdad de las cosas, en palabras de Platón, no es más que una medida exacta o perfecta según aquellos que conocen directamente sus doctrinas al decir de Reale (2001, p. 233); por ello, el sabio, al perseguir el orden, asiste a quienes no otean lo laxo como riesgo para el bienestar. Todo lo dicho respecto al significado del bien se ilustra en la célebre alegoría de la caverna:

Represéntate hombres en una morada subterránea, que tiene una entrada abierta a la luz. En ella están hombres atados de piernas y cuello [...] Arriba se haya una luz de fuego que brilla detrás de ellos y junto al fuego y a los prisioneros hay un muro construido [...] del otro lado pasan sombras que llevan variados utensilios [...] Examina ahora que uno de ellos fuese forzado a levantarse y a marchar hacia la luz. Con respecto al sol concluirá que es lo que gobierna todo en el ámbito de lo visible [...] Y si se acordara de su primera morada y de sus compañeros todavía cautivos ¿̇no piensas que los compadecería? (República VII, 514a-517a)

La temática del fragmento citado no es más que un asunto ético el cual goza de importancia dentro de la filosofía platónica y, por demás, es abordado en prospectiva de un Estado ideal que tiene sus fundamentos en el conocimiento de aquellas ideas facilitadoras del bienestar. El sentido que suministra el tratamiento de esa alegoría resume formidablemente el ideario platónico y, al mismo tiempo, dedica esfuerzos por explicar el ejercicio del saber y sus implicancias éticas por medio de signos presentes en el relato. 
Sucede a dicha narración, la interpretación de las imágenes expuestas, a saber: la morada-prisión, el fuego, las ataduras, la marcha fuera de la caverna, la luz del sol y el retorno a la caverna:

La región que se manifiesta por medio de la vista es la morada-prisión, la luz del fuego es el poder del sol [...] el ascenso y contemplación de las cosas de arriba es la ruta del alma hacia lo inteligible, hacia la verdad. (Republica VII, 517b)

En otros términos, las sombras representan la percepción del mundo sensible y el sol, que al iluminar todo propicia la vista al hombre, es el que permite ver las cosas en sí mismas; luego, ese escape fuera de la caverna representa el ascenso al mundo suprasensible en el que converge el bien representado en el sol. A grandes rasgos, la contemplación de las ideas significa su reconocimiento, y estas no derivan de la percepción ofrecida por el mundo sensible al ser caracterizadas por el mismo Platón, según Rowe (citado en Herrmann et ál., 2007), como principios cósmicos que dan forma, sentido y existencia al mundo (p. 25). No obstante, esto no lleva desconocer para las sensaciones su intervención en procesos de conocimiento, como lo advierte Boeri (2007) dada la capacidad que tales

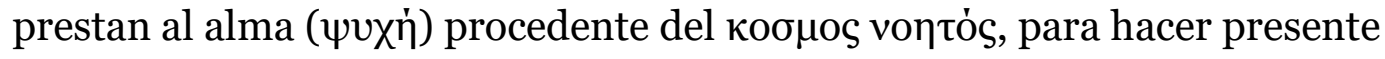
en ella (ảvó́ $\mu \nu \eta \sigma ı \varsigma \tau \tilde{\omega} v \varepsilon ı \delta \tilde{\omega} v)$ los objetos de conocimiento.

Aunque no puede decirse categóricamente que conocimiento es percepción conserva la verdad que contiene el análisis sensualista del fenómeno de un conocimiento entendido en términos de aisthesis. El no hacerlo significa eliminar el aspecto sensible de la percepción humana, y de un modo general, la manera en que el ser humano se conecta con aquello que es externo a él [...] Es más, a pesar de la recomendación de procurar separarse de lo corporal para lograr alcanzar "lo en sí" Platón mediante la idea de reminiscencia nos recuerda la importancia de la percepción como paso previo para el acceso a lo real (pp. 112-113). 
Las percepciones, en tanto derivan del contacto con objetos de la experiencia y con los que se sirve el hombre para comprender su entorno, participan en el proceso del saber. No obstante, este proceso no queda reducido a la simple captación sensible puesto que, como se ha indicado, existe un desplazamiento desde lo empírico a la intelección por medio de las عĩon. Ahora bien, pensar las ideas como principios causativos de mundo las cuales se imponen al hombre para ser seguidas por ser buenas, es erróneo afirmar con ello, según McCabe (citada en Gill, 2005), que su valor es independiente de la persona que las acepta (p.213). Con esta precisión, Châtelet (1995) comenta, acerca de la teoría de las ideas, que el status universal de intelección de estas es la simple forma de paliar una posible contradicción que suministra el status empírico a través de conjeturas, de hipótesis: "Poco consciente de su poder es ese intelecto que se encierra en los límites hipotéticos [...] el mundo inteligible está para que el hombre quede a salvo del inevitable absurdo" (p. 99).

Por lo que sigue al proceso de percepción y su consecuente abstracción del universal, se deduce la capacidad humana para percibir directamente la verdad en la contemplación de las ideas, es decir objetos de conocimiento que, al ser captados conceden el alto rango del saber, definido por el

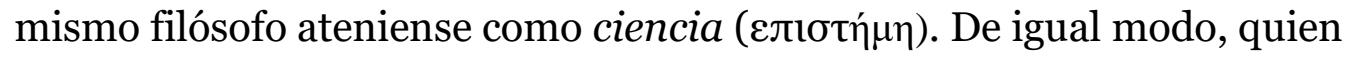
logra el conocimiento de las عíf $\eta$ (ideas o conceptos del entendimiento), está en la capacidad de comprender el bien, cuyas consecuencias prácticas resultan de mucho provecho para las acciones humanas. Estas constituyen la expresión del bien individual, en tanto compromete a la persona en su aforo racional para imponerse sobre sus deseos desenfrenados, y el bien social, por cuanto comprende la formación de relaciones armónicas entre clases sociales y la dinámica que cada una de estas realiza, en sus posibles facultades, para el bienestar de los demás (República, 443d-e). 
En resumen, tanto connotaciones ético-políticas como principios de conocimiento resultan manifiestos en la alegoría de la caverna.

Explícitamente, el hecho de conocer las ideas y dejar la simple intelección de estas para retornar a quienes las desconocen y comunicar lo conocido es el acto de responsabilidad que adquiere el бopós de cara a la ciudad para que todos sus miembros alcancen igualmente aquel conocimiento del bien. He aquí el vínculo de virtud y bien, vínculo que el mismo Platón sitúa en términos de justicia y sensatez para la consecución de un bienestar: "Tanto

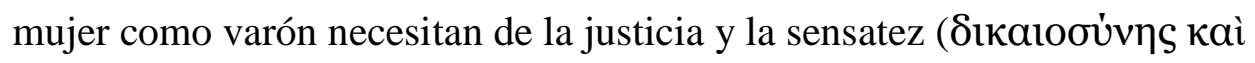

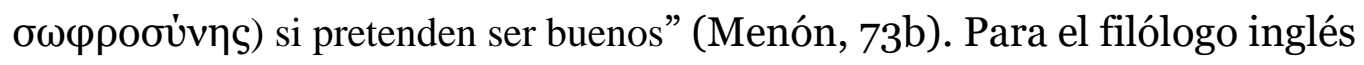
Guthrie (1990), "la forma del bien es causa de todo lo justo y bueno que existe por doquier, y sin la cual nadie puede actuar con sabiduría" (p. 493). Entonces el bien del hombre, en tanto de bienestar se trata, tiende a darse por medio de una actitud virtuosa, cosa que para Platón es determinante a la hora de elegir los medios que conducen al bien, aunque este le sea inherente al hombre. De hecho, una carencia de virtud no supone de absoluta corrupción en la naturaleza humana, puesto que el accionar pérfido no es innato a la persona en tanto le es propio desear el bien, y este actuar nocivo ocurre por el desconocimiento (ä $\gamma v o 1 \alpha)$ de lo provechoso. En esencia, una falta de virtud equivale a la ignorancia, más para efectos contrarios, y el hecho de actuar virtuosamente sobreviene a la recta comprensión del bien por cuanto estima el bienestar de otros. Anexo a esto, el conocimiento del bien comporta un estado integral de perfección moral que luego se evidencia en los actos, que benefician al individuo que practica estos en el medio al que este pertenece. 


\section{Consideraciones finales}

Semejante al tratamiento gnoseológico, el asunto ético trasvasa los distintos diálogos que de Platón se conservan, pero la evidencia de una incesante interrogación por la virtud que se concretiza en un esfuerzo por la definición de la amistad, la templanza, piedad, valentía, la belleza, entre otras, revela un acérrimo interés por parte del filósofo hacia el ámbito moral del ser humano.

Ahora bien, el argumento de la teoría de las ideas ya mencionado, además de ser tal el soporte para todo el entramado de cuestiones que aborda, a saber: lo ético, político, gnoseológico, antropológico, epistemológico, cosmológico y educativo, es también el fundamento de superación del relativismo y escepticismo que en su tiempo dejó en suspenso la existencia de valores universales. Este es el caso de las proposiciones filosóficas de los sofistas, académicos y posteriores escépticos, valores que orientan a las comunidades griegas en sus prácticas cotidianas.

Identificar, entonces, la virtud con el conocer, el saber de lo justo y lo bueno tanto para el individuo como para el colectivo en el que este se inserta es peculiar del intelectualismo ético, cuyo referente es el bien para la construcción de un Estado ideal. Asimismo, una asociación de ética con política es notable en Platón y, en esta óptica lo que por virtudes se asume conduce a la unidad de hombres dispuestos que desean contribuir con el bien de la ciudad considerando, de antemano, que es ella misma la que ofrece, a todos sus miembros, posibilidades de desarrollo moral. De este modo, aunque la práctica de la justicia revela al hombre el ser una virtud esencial para las relaciones entre civiles, es necesario también, en aras de la realización del Estado perfecto, comprender lo justo y el bien universal, lo cual implica que por las acciones e ideas/formas recíprocamente articuladas se alcanza conocimiento (Annas, 1981, p. 211). 
Allende a esta descripción, Platón retorna a la naturaleza humana para tratar de someter a examen la disposición de los seres humanos respecto a una moral en condiciones apropiadas, para lograr el desarrollo social querido. Así pues, ante la constante necesidad humana por la satisfacción de deseos que, como advierte Guthrie (1990), "si dejan que tomen la delantera puede desarrollar una condición patológica [respecto de la analogía platónica de la salud corporal] en la cual la capacidad de resistencia ya no está en el poder humano" (p. 560), los deseos degenerarían en notables perjuicios. Contra ello, el mismo Platón repara que los hombres son más que los simples impulsos apetitivos; esto deriva en una triada axiológica que corresponde al dominio de la razón en cada parte del alma: la sabiduría, la fortaleza y la templanza que ejercen su dominio en la irascibilidad y concupiscibilidad, inherentes a los seres humanos (República, 442c-d).

En síntesis, dado que el hombre es más que simple apetencia y conocer sensible, por cuanto que los objetos percibidos no son únicos objetos del saber según la identificación de conocimiento con percepción, y un conocer cosas que dado a la razón puede alcanzarse por la purificación de deseos, prorrumpe en un estado armonioso que contribuye al seguimiento del bien deseado. Dicho de otro modo, la perfección moral es efecto de la perfección intelectual, una tendencia para posicionar la facultad racional en materia de ética, y cuyo propósito no es más que someter lo teórico y práctico al propósito de discernir lo bueno. Con esto, la relación del saber y el modo de vida del ser humano, modus vivendi que concierne a lo ético y lo moral, significa para la actividad intelectual un principio de acción, si bien aquella no se queda retenida en simples teorías, pues toda acción exterioriza, hace patente y revela lo que en dicho teorizar profieren los seres humanos. 


\section{Referencias}

Annas, J. (1981). An introduction to Plato’s Republic. Belief, knowledge and understanding. Oxford University Press.

Benson, H. H. (2006). A Companion to Plato. Platonic Epistemology, Ethics and Metaphysic. First Published. Blackwell Publishing.

Boeri, M. (2007). La apariencia y realidad en el pensamiento griego. Ediciones Colihue.

Cornford, F. M. (2007). Teoría platónica del conocimiento. Paidós Ibérica.

Conford, F. M. (1989). Platón y Parménides. Editorial Visor.

Châtelet, F. (1995). El pensamiento de Platón. Editorial Colección Labor.

Guthrie, W. (1990). Historia de la filosofía griega IV. Platón. El hombre y sus diálogos. Editorial Gredos.

Herrmann, F-G., Penner, T. y Cairns, D. (2007). Pursing the Good. Ethics and Metaphysics in the Republic. Edinburgh University Press.

Nuño, J. (1988). El pensamiento de Platón. Teoría política y problemas éticos. Fondo de Cultura Económica.

Platón. (1988). Diálogos IV. República (Eggers Lan C., trad.). Editorial Gredos.

Platón. (1988). Diálogos III. Fedón, Banquete y Fedro (García Gual, C., Martínez, M., y Lledó Iñigo, E., trads.). Editorial Gredos.

Reale, G. (2001). Platón. Búsqueda de la Sabiduría Secreta (Heraldo Bernet R., ed.). Editorial Herder.

Ross, D. (1993). Teoría de las ideas de Platón. Ediciones Cátedra. 